\title{
Arbor
}

\section{La distribución del objeto artístico}

\author{
Rosina Gómez-Baeza Tinture
}

Arbor CLXV, 649 (Enero 2000), 103-108 pp.

\section{Mecenazgo y Coleccionismo Corporativo}

«De ahora en adelante una empresa podrá elegir entre el mecenazgo y el patrocinio, del mismo modo que puede hacerlo entre campañas de relaciones públicas y publicidad. Es una mera cuestión de estrategia. Creo que, para una empresa, el mecenazgo constituye un mejor medio de comunicación que el patrocinio ya que, al estar relacionado con la cultura por el valor semántico de su propio nombre, resulta más intelectual y cualitativo» (Alain-Dominique Perrin, Cartier International, «Art and Business», pág. 208).

El futuro del arte y la empresa depende de que se llegue a entender plenamente el concepto de mecenazgo. Tanto si una empresa crea una fundación como si decide que el arte forme parte de la corriente principal de su actividad empresarial, los programas de arte pueden constituir una herramienta de gestión e imagen altamente eficaz que puede favorecer la percepción de la empresa en su entorno social. Los estudios más recientes parecen demostrar que el arte y los negocios pueden ser recíprocamente beneficiosos.

De acuerdo con el uso moderno, la palabra «mecenazgo» -que no ha de confundirse con filantropía ni con inversión- describe una forma relativamente pura de apoyo al arte según la cual se da ayuda a los «creadores» de cultura, no tanto con el fin de obtener directamente una ventaja monetaria o de imagen, sino más bien de aumentar y facilitar el acceso al proceso creativo. Son inherentes al término mecenazgo las propiedades de perfección e innovación.

El propio coleccionismo de arte, por parte de las empresas, se encuentra en auge. Esta actividad que, normalmente, consiste en adquirir 
obras de arte para instalarlas en las zonas de acceso al público y en las oficinas de las sedes empresariales, aumenta día a día. Pero también se están experimentando otras innovaciones en este campo, tales como la creación de museos y salas de exposición a cargo de empresas, colecciones instaladas en los espacios de la sede social y proyectos realizados, en el ámbito público, conjuntamente con entidades y organismos.

Una actividad de mecenazgo seriamente concebida puede ofrecer a las empresas caminos alternativos para invertir en calidad e iniciar su participación en el mundo del arte. Este notable descubrimiento se basa en un cambio de orientación de lo social a lo cultural, es decir, de la filantropía al mecenazgo.

La mayor parte de las empresas conciben el mecenazgo como la labor de una fundación empresarial. Muchas empresas multinacionales han establecido fundaciones cuya relación con todas las artes ha producido proyectos de calidad que les han aportado reconocimiento y prestigio mundial. Pero existen también otras fórmulas. Un programa de arte corporativo que surja de dentro de la propia empresa puede resultar igualmente efectivo.

Cuando el mundo empresarial centra su interés, cada vez más, en los resultado económicos, aquellas empresas que se embarcan con éxito en proyectos artísticos comprenden que el arte puede formar parte de una nueva estrategia para alcanzar sus objetivos. La expresión visual ya no es simplemente un bonito cuadro para colgar en la pared, sino que se ha convertido en el mejor mensajero para interesar y atraer poderosamente a amplios segmentos de la población. Constituye también un modelo de conducta empresarial, una muestra de apoyo a la propiedad humana del conocimiento y la mejor manera de fomentar la educación y la cultura.

La ampliación de la esfera de responsabilidad que la empresa ha de asumir justificaría la creación de una plataforma que, desde una perspectiva social de fomento de la tolerancia, la creatividad y el libre discurrir de las ideas, promoviera la relación entre el sector privado y la creación artística, favoreciéndose la realización de programas dedicados a las artes visuales.

El concepto de coleccionismo de arte corporativo ha ido evolucionando de una participación pasiva a una activa y no solo en el propio lugar de trabajo sino a nivel regional, nacional y mundial, para uso y disfrute de públicos cada vez más diversos y numerosos, por lo que no resulta gratuito reseñar que el auténtico mecenazgo demuestra que el apoyo a las artes, por parte de la empresa, constituye un activo cultural, nunca un acto caritativo. 


\section{La distribución del objeto artístico}

FiguRA 1. "Coleción Recorridos Fotográficos de Arco». Gabriel Cuallado ()

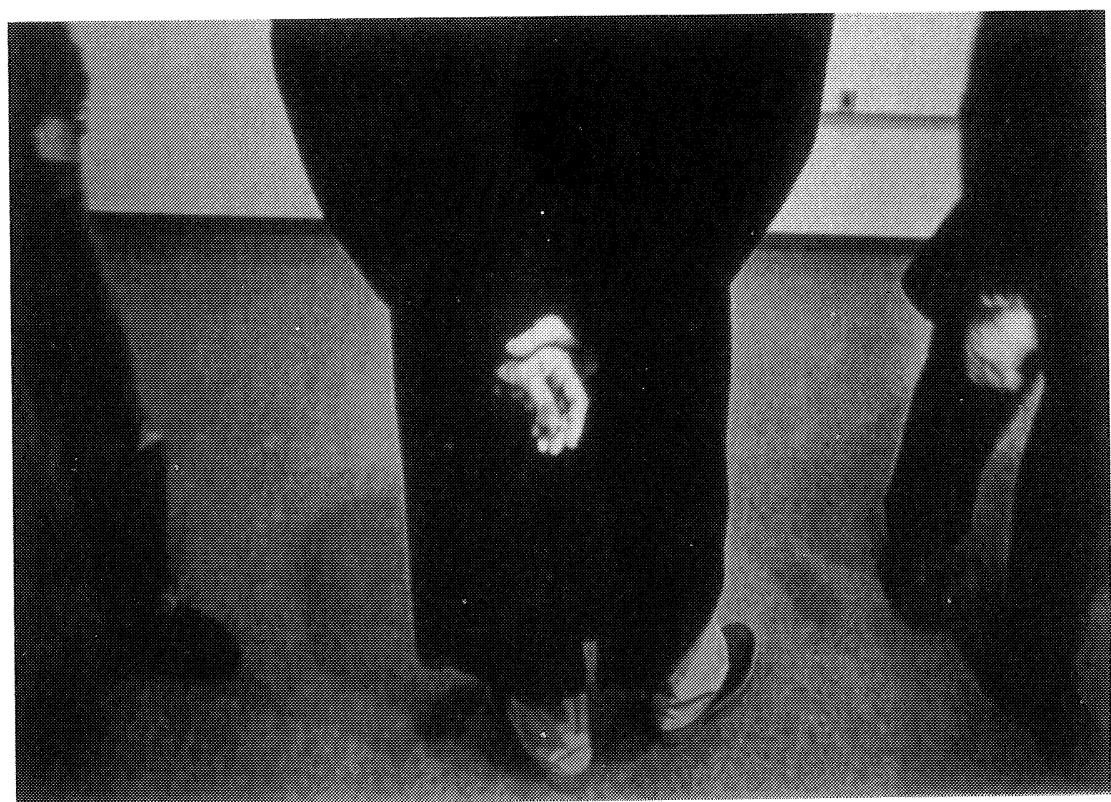

Figura 2. "Coleción Recorridos Fotográficos de Arco». Toni Catany (

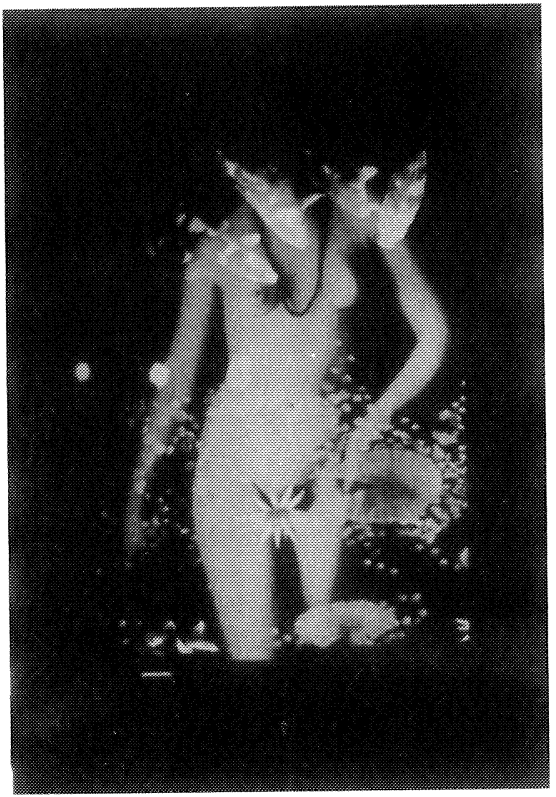




\section{Rosina Gómez-Baeza Tinture}

FiguRA 3. «Coleción Recorridos Fotográficos de Arco». R. Navarro (C)

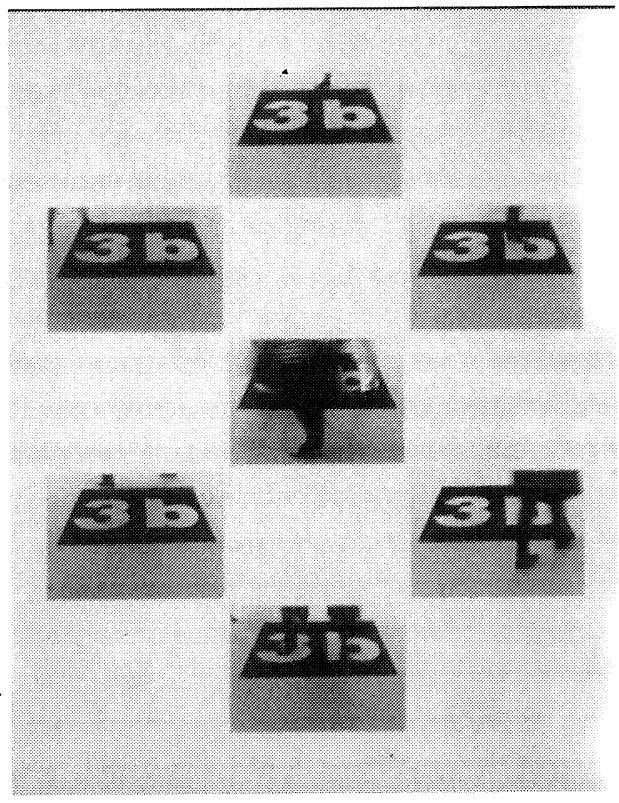

Figura 4. «Coleción Recorridos Fotográficos de Arco». Milagros de la Torre (C)
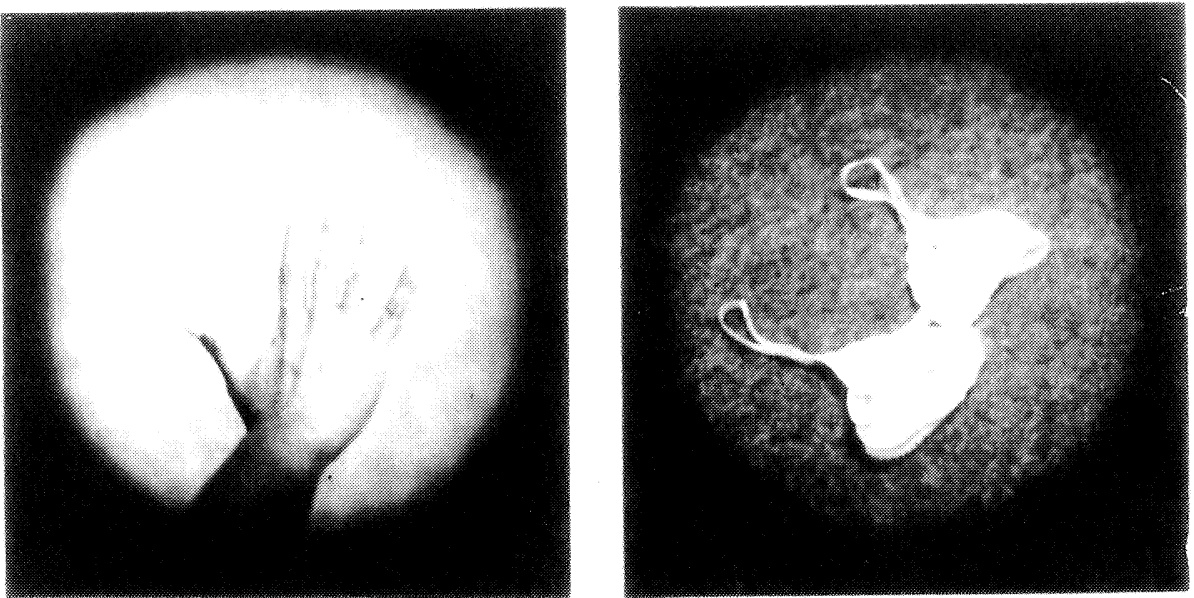


\section{La distribución del objeto artístico}

Figura 5. "Coleción Recorridos Fotográficos de Arco». Jorge Ribalta @

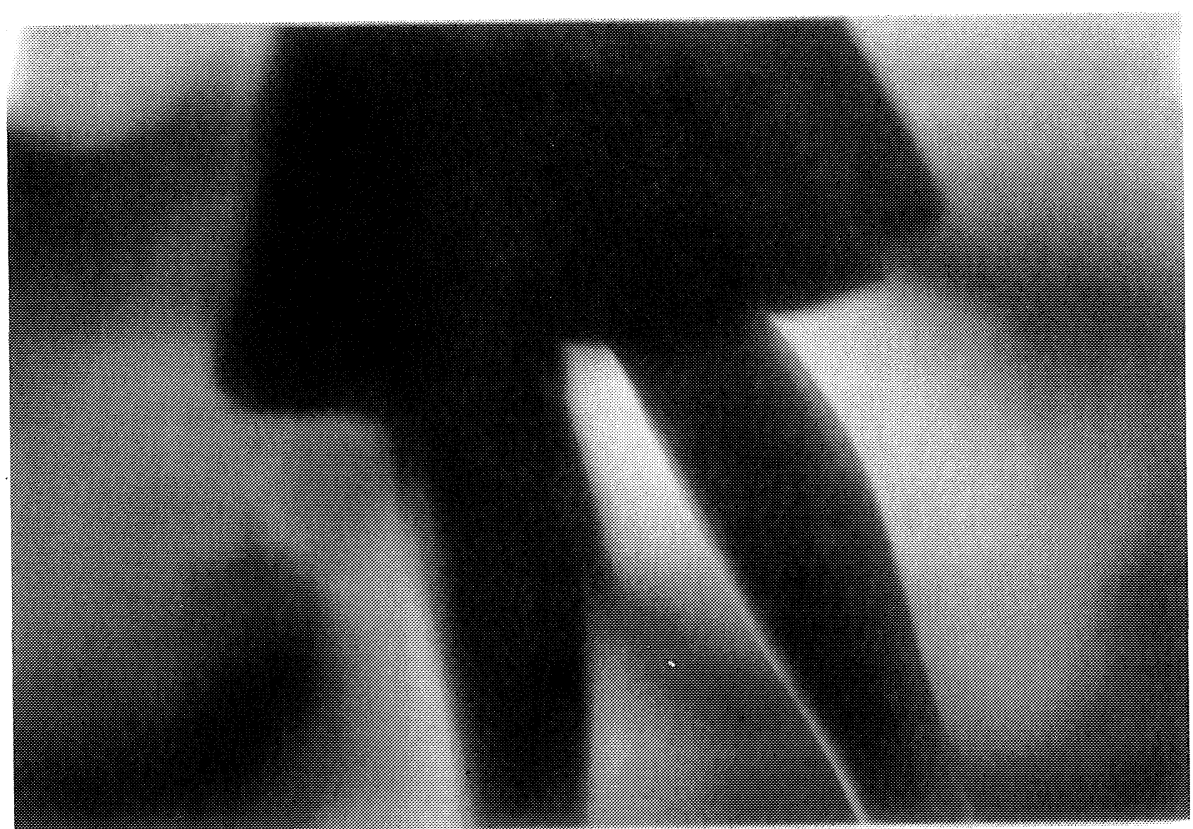

FiguRA 6. «Coleción Recorridos Fotográficos de Arco». Humberto Rivas (C






\section{Rosina Gómez-Baeza Tinture}

Figura 7. "Coleción Recorridos Fotográficos de Arco». B. Plossu (

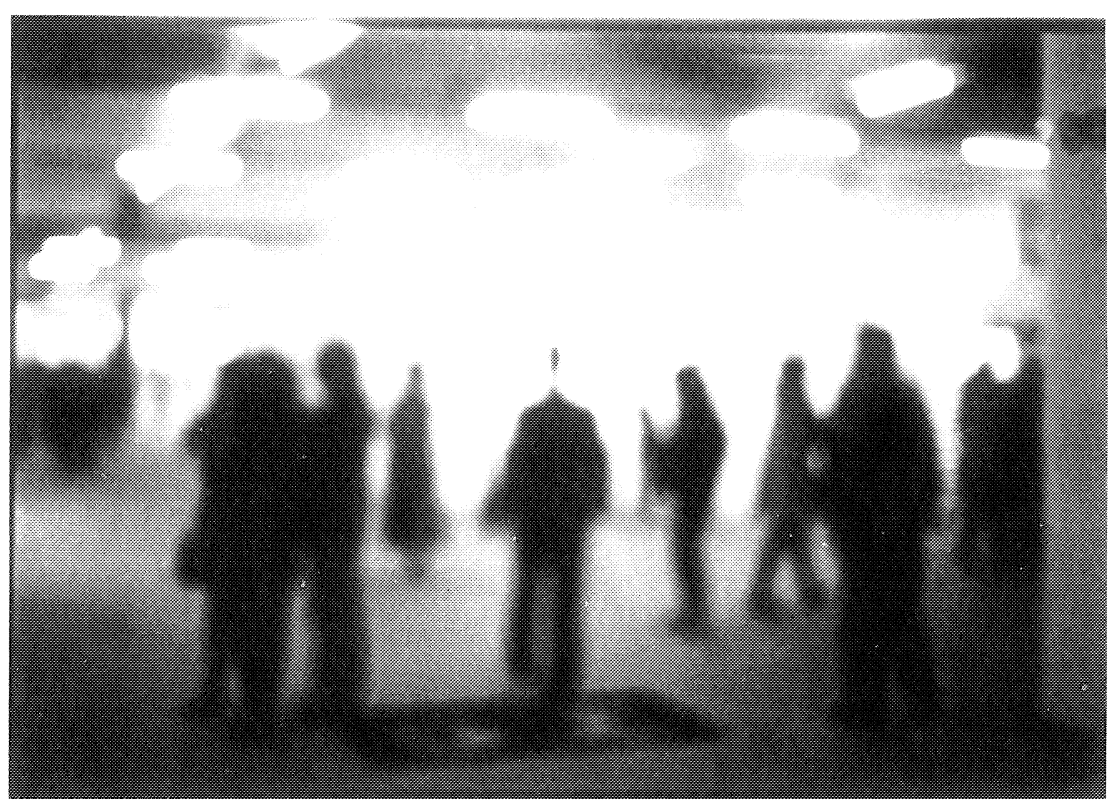

